\title{
A Student's Experience and View on College Teaching and Learning
}

\author{
Kristin Atkinson, BS \\ Texas A\&M University - Central Texas
}

\begin{abstract}
Through my college experience and my reflection on The Scholarship of Teaching and Learning Reconsidered, I have come to recognize several ideas that have greatly impacted me, my views on learning, and my actual learning. My overall experience in college has been beneficial because of the teachers who approached teaching with a more conscious effort and taught me to approach learning and my role as learner in the same way. This essay highlights many of the aspects of the chapter, "Teachers and Learning," that have been beneficial for me throughout my educational career, and a few notes on changes that may have helped.
\end{abstract}

Entering college, I assumed that my professors were teachers who would pour their vast knowledge and understanding into me, an eager and willing pupil. I entered with expectations of challenging, thought altering course work and stimulating lectures. I envisioned understanding things I could never grasp before. It was not that I was excited just by the idea of learning new information; I was excited also to be taught by experts. However, I had little understanding of the roles faculty members played in the university setting, how learning really occurred, or what teaching even was. I thought that professors were foremost teachers without other professional obligations, that teaching was the dissemination of knowledge, and that learning was a passive affair.

Unfortunately, this ignorance and my actual experience in college classes led me to the erroneous belief that being a college professor must be an easy job: write up a lecture, take a few questions from the textbook, assign a term paper, grade... repeat. I felt this process was the only work many of my teachers were doing. I did not know if I was really learning anything, and I was starting to question the point of a college "education." I could not figure out why the passions my professors had towards their subjects did not translate to amazing, innovative teaching and automatic learning.

I did notice, however, that not all of my professors were merely giving me information and then testing me on it; some were actually teaching me material and processes that I understood, remembered, and used! In fact, these teachers had a much larger impact on me than simply guiding me through my learning in their courses. They helped me realize the more active effort that learning requires and encouraged skills and habits that helped me succeed in all of my classes. I also eventually recognized that professors do more than just teach; they also have research, publishing, and organizational obligations, all requiring time and effort.

Though I now realized that teaching was not my professors' only role within the university, I never would have imagined it was not the most important. I had heard the old saying, "publish or perish"; however, it was not until reading The Scholarship of Teaching and Learning Reconsidered that I realized the implications this mentality has on teaching at the university level. It stands to reason that when tenure is contingent on publications, this aspect of the job becomes the faculty's priority. Though I am sure teaching is not covertly expressed as unimportant, this seems to be the unintended message sent to students through organizational policies, tradition, and most obviously, ineffective instruction. I never imagined that teachers were not encouraged to approach classes as they approached other aspects of their role as academics. Like every other "truth" that requires research to be supported and publication to be replicated, the effectiveness of teaching should be critically analyzed and empirically tested. This process is what is most admirable about scholars of teaching and learning; they do not take their teaching 
methods at face value. Their work seems completely appropriate as the world of academia revolves so much around research and peer reviewed publications where nothing can be assumed, including the presence of effective teaching and learning.

Given the inconsistencies in my learning experiences and the discrepancies between my most and least effective teachers, I am relieved that the importance of the scholarship of teaching and learning (SoTL) is becoming a conversation in so many universities around the country. As a student, I am grateful for professors who seem to genuinely care about student learning and recognize the importance of approaching teaching with a conscious effort. My appreciation is now better articulated after reading The Scholarship of Teaching and Learning Reconsidered because it prompted me to reflect and examine the role my teachers played in my education throughout my college career. I thought about the teachers I had, the courses I loved, and the ones I hated. I analyzed my favorite assignments and the few that just wasted time. Several topics stood out to me as I compared my experiences with the ideas and changes discussed in the chapter, "Teachers and Learning."

The remainder of this essay highlights the aspects of SoTL that I found the most beneficial for students' overall success, and addresses a few topics that were important in my personal experience. Foremost, the student's active role in learning was missing from the discussion in "Teachers and Learning." And, though student input was mentioned by Hutchings, Huber, and Ciccone (2011), allowing learners more participation in SoTL may be beneficial to the organization's goals. Also, the most prominent theme of SoTL, inquiry and analysis into teaching and learning, can be the prominent theme that guides student learning. Finally, I close with some notes on the evidence of learning and what would have helped jumpstart me in the beginning of my academic journey.

\section{Students' Role in Learning}

It is interesting that the idea of the "teaching gift" has begun to lose traction, because over the years I have let go of the idea that the ability to learn is a gift (Hutchings et al., 2011, p. 25). It is becoming evident that it takes active and conscious effort not only to become a great teacher but also to become a great learner. When I recognized learning as an acquired skill, I gained much confidence in my ability to learn and succeed in school. Teachers may be able to foster this change in assumption by helping students understand how learning occurs, and encourage their students to approach learning with a conscious effort. Learning should not be seen as a passive event, which is commonly assumed in a lecturebased classroom where the teacher seems to have the only active role. Instead, I believe clear and explicitly stated goals to be active learners and to view learning as a skill can be beneficial. Many students may not have ever heard this information! Course syllabi provide students with information about what they will be learning, but they typically fail to mention the best ways to learn it. Too, critical thinking skills and practices of inquiry and analysis can be applied to discovering students' own learning styles and becoming better learners.

Student receptivity is also a vital piece of the learning process. For instructional methods to be successful, students must be receptive to them. How a student approaches a class is just as important as how a teacher approaches it. Again, explicitly stated goals can help facilitate learning by getting students and faculty to develop a shared understanding of the purpose of classroom activities. Students may see assignments as "busy work" if they do not understand the purpose of the task. Additionally, for students to know why they are doing an assignment or project helps them draw connections from classroom learning to its practical application in the real world.

Encouraging students to become active learners and explaining the processes of learning may also benefit the student-teacher relationship. Students and teachers have opposite roles within the classroom but the same goal of furthering student learning. Instead of students and professors being divided by 
differences in the power of their roles, teachers can instead be viewed as facilitators of learning, but this perspective is one that students will need encouragement to take.

\section{Feedback Includes Students in SoTL}

Themes expressed throughout the "Teachers and Learning" chapter regarding the SOTL movement are that discourse provides inspiration for change, and collaboration enhances the effort's success. I believe that SoTL success can be furthered by including student involvement and allowing learners to join in this conversation and collaboration. Perhaps the most obvious way to find out what students are learning is to ask them. Student feedback not only provides teachers with helpful information and evaluation of courses, but it also allows the learners an occasion to evaluate their own learning process and what they actually learned. I have been grateful for opportunities to tell my teachers that a writing assignment was particularly helpful, or that an instruction was confusing. Such student feedback requires evaluation and analysis, which are higher level thinking processes, according to Bloom's taxonomy, and are important for learning. For example, through course surveys that target higher level thinking, I have realized how powerful writing is for my understanding of course material, and I have been able to amalgamate all the seemingly disjointed ideas presented in a course into one coherent and solid understanding of the subject. Teacher feedback is incredibly helpful to students; maybe students' feedback can be similarly helpful for teachers.

\section{The Skills and Habits for Success}

In the chapter, "Teachers and Learning," the role that inquiry and analysis played in SoTL stood out to me. The scholars of teaching and learning used inquiry and analysis to discover gaps in their knowledge of the teaching and learning process. Specifically, Ciccone's course at the University of Wisconsin aimed to foster these habits in students to create complex thinkers, and the LEAP learning outcomes now represent that same focus (Hutchings et al., 2001). To me, these skills are the most valuable practices teachers can encourage in their students because their application and uses are vast and have been paramount in my development as a learner and an independent adult. Fostering these skills within the classroom would not only help students grasp the course material but also give students the skills that will be beneficial in many aspects of life, including learning in general.

In classes where analysis, synthesis, and evaluation are the main components of learning, the lower level processes of knowledge, comprehension, and application are inevitable and more meaningful. For example, questions and projects that require students to synthesize information by creating a plan, or analyze a problem by distinguishing the relationships involved, also require and support the lower level thinking skills such as knowledge and comprehension. To construct a plan or analyze a problem, students have to know the terms and understand the concepts before these can be applied to the task at hand. A traditional lecture is the presentation of knowledge, but it cannot be assumed that students have made a habit of using the higher level thinking skills necessary to really apply, analyze, and synthesize that knowledge. To use these skills, teacher guidance is critical. It makes a difference when teachers are constantly asking questions of their students and providing work that requires different forms of critical thinking. Not only does this repeated engagement force students to think more deeply about the topic, but students also then mirror this inquiry and analysis when working through problems on their own. Through more sophisticated assignments and interactive lecturing, higher level thinking skills become habits and tools that enable students to be successful. 
Also, the same self-reflection that SoTL requires of teachers can be applied to students during learning. The simple act of looking back on the information presented can lead students to connect separate ideas. This process can even be applied to learning about learning. For example, reflective analysis may empower students to become actively invested in their profession of learner through awareness of their own learning process.

\section{Evidence of Learning}

Evidence of learning is necessary for teachers to assess their teaching methods and for students to track their own progress. Clearly, students are responsible for providing this evidence, but it is important to remember that the evidence students provide is based on what is asked. Students cannot show their rich understanding of a complex topic by answering a few simple questions pertaining to it. The form of the assessment has the ability to change the outward appearance of learning. Also, the assessment type shapes the way in which students prepare for the examination. Shallow test questions encourage superficial learning, whereas more complex and thought-provoking questions promote more meaningful learning of the test material.

Too, it is worth noting that students want to know that they are learning. Students gauge success in a course not merely by the grade received at the end of the semester, but also by the course's value in their overall educational and career goals. Students' ability to apply the knowledge gained in the classroom to the real world provides evidence of learning, and it brings value to that learning. At the end of the college career, students progress from learners to appliers. They want to know the knowledge and skills received through their academic careers as students can be put into motion and used. Teachers bring value to course material when they present it as a valuable addition to everyday life.

\section{Transitioning into College and Beyond}

The changes in thinking that have defined me as a learner developed slowly over time through my experience as a student. Several events and teachers led to epiphanies that became my educational mantra. Through this, I realized I needed to stop limiting myself by my preconceived ideas of what it means to be smart and how I measured up to that definition. Instead of thinking in terms of innate ability, I began to think in terms of potential ability. I realized I could learn to be a good learner and through that process become prepared for life after college.

I believe freshman seminars, like those being used at University of Wisconsin - Milwaukee, can do a great service for incoming students making the transition into college (Hutchings et al., 2011). In addition to fostering the skills of inquiry and analysis, they can help students learn about learning and understand their active role in their education. Had this been available to me as a freshman, maybe I would not have wandered so aimlessly through my first few semesters, wasting time trying to figure out what I was doing, what my teachers were doing, and how to be successful.

Fortunately, I did craft an understanding of how to get the most out of my college experience, and as a recent graduate, I realize that the processes and skills advocated in this essay for learners are vital to life after college. Higher education should extend beyond the simple transmission of knowledge and aim to produce graduates who have critical thinking skills that can be used in many aspects of life. Learning and decision making through inquiry and analysis will encourage independent thinkers who can effectively consume the information presented to them on a daily basis. Everyday tasks, family and job responsibilities, and social and political beliefs substantiated by critical thinking and evidence can have a powerful impact on the individual and society. Professors who teach students how to think, instead of merely what to think about, are key to this development. 
Finally, I want to stress that it was the teacher, not the subject, school, or delivery method, that made classes interesting and made learning more effective for me. Regardless of teaching styles or preferences, those courses that I finished with a sense of accomplishment and meaningful knowledge were based, more than anything else, on the instructor's engagement with the students. It is absolutely clear to students when they have a teacher who really wants to help them succeed. This support and guidance allows students to thrive and take the risks associated with learning. Thank you, teachers; you absolutely make a difference.

\section{Reference}

Hutchings, P., Huber, M. T., \&

Ciccone, A. (Eds.). (2011). The

scholarship of teaching and learning

reconsidered: Institutional integration

and impact. Stanford, CA: Jossey-

Bass.

Kristin Atkinson is a lover of learning and a grateful participant in this project. Kristin recently graduated Summa Cum Laude from Texas A\&M University -Central Texas with a Bachelors of Science in Psychology and is currently working as a research assistant within the university. She is interested in continuing her education but is choosing to further explore and narrow down her interests within the field of psychology before embarking on the graduate school journey. Kristin presently lives in Washington State with her husband and two young sons who provide her with constant encouragement and new opportunities to learn. 